\title{
Artikel
}

\section{Giften en woonplaats, een Belgische federale wetswijziging}

\author{
Mr. dr. K.M.L.L. van de Ven*
}

\section{Inleiding}

Aanleiding voor deze bijdrage is de Belgische wetswijziging die op 15 december 2020 in België is ingevoerd, met als doel heffing van registratierechten mogelijk te maken over roerende giften die in een buitenlandse notariële akte zijn opgenomen. Het betreft een fiscaalrechtelijke wijziging op federaal niveau, die derhalve voor alle Belgische Gewesten geldt. Giften die vóór 15 december 2020 voor een buitenlandse notaris zijn verleden, zijn niet onderworpen aan de nieuwe voorschriften en blijven vrij van schenkbelasting. Desgewenst kunnen ze worden voorzien van een zogenoemde 'pacte adjoint'.

In deze bijdrage ga ik in op de wetswijziging, de gevolgen daarvan en de betekenis c.q. de rol van de woonplaats.

\section{Roerende giften via een buitenlandse notaris}

De afgelopen twintig jaren hebben Belgische en Nederlandse onderdanen voor roerende giften veelvuldig een beroep gedaan op de Nederlandse notaris. Daarvoor waren meerdere redenen aan te voeren. In de eerste plaats konden op die manier an de gift schriftelijk voorwaarden worden verbonden, zoals het recht van vruchtgebruik en het Belgische beding van terugkeer. Verder was met de vastlegging van de gift bij authentieke akte onomstotelijk bewijs geleverd van de datum van de schenking. Die datum is van belang voor het fiscaal gezien buiten de nalatenschap houden van de schenking. Ten slotte was het veel hogere honorarium van de Belgische notaris een reden om de Nederlandse notaris in te schakelen; in België hangt de hoogte van het honorarium (ereloon), in tegenstelling tot die van zijn Nederlandse collega, af van de waarde van de schenking.

Dat de schenking via deze route vrij van schenkbelasting kon worden gedaan, is weliswaar relevant, maar vormt op zichzelf geen reden om een buitenlandse notaris in te schakelen. De schenking kon en kan immers ook zonder buitenlandse notaris vrij van schenkbelasting worden gedaan (zie par. 4.2 hierna).

De weg van de onbelaste roerende hand- of bankgift staat na de Belgische wetswijziging van 15 december 2020 nog altijd open voor in België woonachtige schenkers en begiftigden. Dat is het gevolg van het feit dat de Belgische schenkbelasting wordt geheven in de vorm van een registratierecht, en uitsluitend verschuldigd is als de schenking ter registratie wordt aangeboden.

Die registratie is alleen verplicht als de notaris een authentieke akte heeft opgemaakt. Voor de schenking van een onroerende zaak en van niet-beursgenoteerde aandelen is deze authentieke akte een constitutief vereiste om de overgang van de eigendom te realiseren. 


\section{De wetswijziging en de reden ervan}

Blijkens de memorie van toelichting ${ }^{1}$ bij het op 17 juni 2020 bij de Belgische Kamer van volksvertegenwoordigers ingediende wetsvoorstel is de bedoeling van de wijziging steeds geweest het onmogelijk maken van wat is genoemd 'de kaasroute'. ${ }^{2}$ Het belang van deze wetswijziging is in deze toelichting onderstreept met de vernietiging op 12 juni $2018^{3}$ door de Belgische Raad van State $^{4}$ van een fel betwist standpunt van de Vlaamse belastingdienst (Vlabel). ${ }^{5}$ Door het standpunt van Vlabel dat betrekking had op de gesplitste aankoop van vruchtgebruik en blote eigendom van effecten of geldbeleggingen ${ }^{6}$ (veelal ouders-kinderen) werden de kinderen bij overlijden van de ouders alleen dan niet belast met erfbelasting over de volle eigendomswaarde, als het geld dat ze voor de aankoop van hun ouders hadden ontvangen aan regionale schenkbelasting was onderworpen. Die voorwaarde van verschuldigd zijn van regionale schenkbelasting sloot de tussenkomst van een buitenlandse notaris bij de schenking uit

Voor deze voorwaarde was in het wetsartikel waar Vlabel naar verwees - artikel 2.7.1.0.1, lid 2, Vlaamse Codex Fiscaliteit VCF - echter geen aanknopingspunt te vinden. Wettelijk gezien volstond het namelijk om te bewijzen dat de blote eigenaar op het ogenblik van de aankoop over voldoende middelen beschikte om de blote eigendom te kopen. Dat de blote eigenaar over voldoende middelen beschikte dankzij een voorafgaande schenking die niet aan schenkbelasting werd onderworpen, vormde geen probleem.

De Belgische Raad van State heeft in zijn arrest van 12 juni 2018 het betwiste standpunt van Vlabel vernietigd, omdat dat volgens hem in strijd was met het legaliteitsbeginsel in fiscale zaken. Datgene wat de wetgever had willen regelen met artikel 2.7.1.0.1, lid 1 en 2, VCF was dat het geld via een openlijke schenking was verkregen door de kinderen, en niet via een zogenoemde 'bedekte bevoordeling'. Dat die openlijke schenking aan schenkbelasting moest zijn onderworpen, was echter

1. DOC $551357 / 001,2019 / 2020$, p. 3, Wetsvoorstel tot wijziging van het Wetboek der Registratie-, Hypotheek- en Griffierechten met het oog op de verplichte registratie van buitenlandse notariële akten.

2. Het gaat hierbij om schenking van roerende goederen door Belgische rijksinwoners die worden verleden door een buitenlandse notaris. Het betreft veelal een Nederlandse notaris, vandaar de naam 'kaasroute'. In de memorie van toelichting op het wetsvoorstel wordt deze term meerdere malen gebruikt. Overigens hebben ook Franse en Zwitserse notarissen deze schenkingen van Belgische rijksinwoners notarieel vastgelegd.

3. Arrest RvS nr. 241761

4. De Belgische Raad van State is een bijzonder adviesorgaan en rechtscollege. De Raad van State staat buiten de rechterlijke macht en maakt deel uit van de rechtsorde. Als bestuurlijk college kan de Raad van State bestuurshandelingen schorsen of vernietigen als deze in strijd zijn met hogere rechtsregels.

5. Standpunt nr. 15004, 1 juni 2016.

6. Met ingang van 1 juni 2017 ook van deelbewijzen van een burgerlijke maatschap die effecten of geldbeleggingen bevat. niet in de wet vastgelegd. Ook de parlementaire geschiedenis bij artikel 2.7.1.0.1 VCF repte niet over een registratieverplichting.

Het wetsvoorstel van 17 juni 2020 wil, aldus de toelichting daarop, een antwoord bieden op het arrest van de Raad van State van 2018: ${ }^{7}$ het standpunt van Vlabel uit 2016, maar dan in bredere zin, krijgt met deze wijziging een wettelijke grondslag, waardoor alle schenkingen van roerende goederen, verleden voor een buitenlandse notaris, verplicht moeten worden geregistreerd.

Artikel 19, lid 1, 6e van het Federale Wetboek van Registratie-, Hypotheek- en Griffierechten luidt met ingang van 15 december 2020 als volgt:

'Moeten binnen de bij artikel 32 gestelde termijnen geregistreerd worden (...): de in het buitenland verleden notariële akten die titel vormen voor een schenking onder de levenden van roerende goederen door een rijksinmoner.'

Artikel 19, lid 2 is eveneens aangepast en luidt als volgt:

'Onverminderd de bepaling onder be van het eerste lid en behoudens wat de bepalingen onder $2 e$, 3e en $5 e$ van hetzelfde lid betreft, morden in dit artikel alleen de in België verleden akten bedoeld.'

Het gewijzigde artikel 35, lid 1, 8e van het Federale Wetboek van Registratie-, Hypotheek- en Griffierechten bepaalt eveneens met ingang van 15 december 2020:

'De verplichting tot aanbieding ter registratie van akten (...) berust ondeelbaar: op de contracterende partijen ten aanzien van de in artikel 19, lid 1, 6e bedoelde akten.'

Het wetsvoorstel van 17 juni 2020 is heel snel, te weten op 7 juli 2020, door de Kamercommissie Financiën aangenomen. De indieners van het wetsvoorstel, zijnde volksvertegenwoordigers uit Vlaams christendemocratische hoek en van partij Ecolo Groen, kregen vanuit de Kamer van volksvertegenwoordigers brede steun. Het doel van de indieners om met de wetswijziging 'het achterpoortje om aan schenkbelasting te ontsnappen', te sluiten, terwijl volgens hen de meerderheid van de rijksinwoners de binnenlandse weg volgt en belasting betaalt, werd binnen enkele maanden gerealiseerd.

De invoering van de nieuwe wettelijke regeling was overigens aanvankelijk gepland op 1 december 2020. Bij

7. DOC 55 1357/001, 2019/2020, p. 5, Wetsvoorstel tot wijziging van het Wetboek der Registratie-, Hypotheek- en Griffierechten met het oog op de verplichte registratie van buitenlandse notariële akten.

8. De leden 2 en 3 hebben betrekking op akten waarbij de eigendom of het vruchtgebruik van in België gelegen onroerende goederen (zaken) wordt overgedragen c.q. wordt gevestigd en lid 3 ziet op huurcontracten van in België gelegen onroerende goederen. De akten waar lid 5 op doelt, zijn die van inbreng van goederen in vennootschappen met rechtspersoonlijkheid, die hun zetel van werkelijke leiding in België hebben. 
amendement van 19 november $2020^{9}$ is de datum van inwerkingtreding echter uitgesteld naar 15 december 2020, met als reden van vertraging dat de behandeling van het voorstel van bijzondere wet ${ }^{10}$ enige tijd vergde. Deze bijzondere wet was vereist omdat deze wijziging van artikel 19 van het Federale Wetboek van Registratie-, Hypotheek- en Griffierechten een zogenoemde bicamerale aangelegenheid ${ }^{11}$ betrof. Zoals uit de toelichting op het wetsvoorstel van 17 juni 2018 blijkt, is, hoewel de vernietiging door de Raad van State op 12 juni 2018 enkel het Vlaamse standpunt betrof, de probleemstelling identiek voor de regelgeving in het Brussels en Waals Gewest. ${ }^{12}$

\section{Gevolgen van de wetswijziging}

\subsection{Registratieverplichting}

Met ingang van 15 december 2020 geldt in België voor alle notariële akten die vanaf 15 december 2020 zijn opgesteld ten behoeve van een rijksinwoner, ook buitenlandse, een registratieverplichting. Deze registratieverplichting geldt, in tegenstelling tot Belgische notariële akten, bij de buitenlandse notariële schenking van zowel roerende als op Belgisch grondgebied gelegen onroerende goederen, voor partijen en niet voor de buitenlandse notaris. ${ }^{13}$ Voor roerende goederen is deze verplichting nieuw, voor onroerende goederen bestaat deze verplichting al veel langer.

De termijn waarbinnen de buitenlandse notariële schenkingsakte van roerende goederen door partijen ter registratie moet worden aangeboden, bedraagt vier maanden na de ondertekening ervan bij de buitenlandse notaris. ${ }^{14}$ Dit betekent concreet dat de partijen een gewaarmerkt afschrift van de schenkingsakte bij de ontvanger van het registratiekantoor zullen moeten overleggen. Indien partijen de akte niet binnen vier maanden laten registreren of de verschuldigde schenkbelasting niet tijdig

9. DOC $551357 / 015,2019 / 2020$ Wetsvoorstel tot wijziging van het Wetboek der Registratie-, Hypotheek- en Griffierechten met het oog op de verplichte registratie van buitenlandse notariële akten. Met een 'bedekte bevoordeling' wordt bedoeld een akte onder bezwarende titel die tevens een schenking inhoudt, zoals een verkoop tegen een prijs lager dan de waarde in het economische verkeer; in Nederland zou in deze overeenkomst een belastbare gift geconstateerd kunnen worden.

10. DOC 55 1635/001 Voorstel van bijzondere tot wijziging van het Wetboek der Registratie-, Hypotheek- en Griffierechten met het oog op de verplichte registratie van buitenlandse notariële akten. Dit voorstel is ingediend op 10 november 2020

11. Het Belgische Federaal Parlement bestaat uit twee kamers (bicameraal): de Kamer van volksvertegenwoordigers en de Senaat.

12. DOC 55 1357/001, 2019/2020, p. 5, Wetsvoorstel tot wijziging van het Wetboek der Registratie-, Hypotheek- en Griffierechten met het oog op de verplichte registratie van buitenlandse notariële akten.

13. Art. 35, lid 1, 2e en 3e van het Federaal Wetboek Registratie-, Hypotheek- en Griffierechten.

14. Art. 32, lid 1, 8e van het Federaal Wetboek Registratie-, Hypotheek- en Griffierechten. Art. 32, lid 1, 4e vermeldt dezelfde termijn voor buitenlandse notariële akten waarbij in België gelegen onroerend goed in eigendom wordt overgedragen of wanneer daarop een vruchtgebruik wordt gevestigd. betalen, riskeren ze een boete die wordt bepaald aan de hand van het bedrag aan verschuldigde schenkbelasting; de ontvanger kan deze boete verminderen tot een minimum van $10 \%$ van de verschuldigde belasting, en deze bedraagt maximaal $50 \% .^{15}$

Of de registraties van buitenlandse schenkingen van roerende goederen tot heffing van schenkbelasting leiden, moeten de Belgische Gewesten zelf beslissen; deze bevoegdheid is immers aan hen gedelegeerd (zie par. 5). In het Vlaams Gewest bestaat, gelet op het hiervoor in paragraaf 3 vermelde oude standpunt van Vlabel van 1 juni 2016, geen twijfel dat schenkbelasting verschuldigd zal zijn. Het gevolg is dan evenwel ook dat over de geschonken goederen geen erfbelasting meer is verschuldigd als de schenker overlijdt. Daarbij is het niet relevant hoe kort of hoe lang voor het overlijden de schenking is gedaan. Artikel 2.7.1.0.5 VCF is immers alleen van toepassing als de schenking niet aan schenkbelasting is onderworpen omdat deze niet ter registratie werd aangeboden. Uitsluitend in die situatie zal de schenking alsnog met erfbelasting worden belast bij de begiftigde, als de schenker, zijnde een Belgische rijksinwoner, binnen drie jaar na de schenking overlijdt.

4.2 Onbelaste schenking van roerende goederen? Schenken zonder schenkbelasting verschuldigd te zijn is in België nog altijd mogelijk. Zo is voor de hand-en bankgift geen registratie vereist, evenals voor de schenking van een levensverzekering door middel van de wijziging van de begunstiging. Bij een handgift kan worden gedacht aan een geldbedrag, kunst of sieraden, bij een bankgift schrijft de schenker het geld of een bepaalde effectenrekening over van de ene naar de andere rekening. Voor deze schenkingen is een notariële akte namelijk geen constitutief vereiste.

Uitgangspunt van artikel 931 van het Belgisch Burgerlijk Wetboek (BW) is dat een schenking onder de levenden bij notariële akte moet worden gedaan. De sanctie op het niet naleven van dit vormvereiste is nietigheid. In de rechtsleer ${ }^{16}$ is echter algemeen aanvaard dat men op een qua vorm geldige wijze ook kan schenken via de hand- en bankgift, en via een zogenoemde 'vermomde' of 'bedekte' schenking. ${ }^{17}$ Deze uitleg wordt gelezen in de tekst van artikel 931 Belgisch BW: 'Alle akten houdende schenking onder de levenden worden verleden voor een notaris (...).' Volgens de rechtsleer betekent dit uitsluitend dat wanneer van de schenking een akte wordt gemaakt, deze notarieel moet zijn. Worden aan de schenking van roerende goederen bepaalde voorwaarden verbonden, zoals voorbehoud van een vruchtgebruik, dan is de notariële akte wel een vereiste.

In de praktijk bestaat veelal behoefte om ook aan de hand- of bankgift voorwaarden (modaliteiten) te verbin-

15. Art. 41 bis van het Federaal Wetboek Registratie-, Hypotheek- en Griffierechten.

16. Zie o.a. E. Goovaerts \& L. Weyts, Notariële akte België, in: A. Verbeke, F. Buyssens \& H. Derycke (red.), Vermogensplanning met effect bij leven: schenking, Brussel: De Boeck \& Larcier 2005, p. 91.

17. Zie noot 8 . 
den. Een reden daarvoor kan zijn dat daarmee duidelijk is dat het om een schenking gaat en niet om een lening. Bovendien ligt met het schriftelijk vastleggen van voorwaarden de datum van de schenking vast, hetgeen van belang is voor de hiervoor reeds genoemde driejaarstermijn, die niet alleen in het Vlaams Gewest, maar ook in het Brussels en Waals Gewest geldt.

Het is mogelijk om de gewenste voorwaarden in een zogenoemde onderhandse 'pacte adjoint' op te nemen. Die mogelijkheden zijn beperkter dan die van een notariële akte, maar een uitsluitingsclausule, ${ }^{18}$ het conventioneel beding van terugkeer, ${ }^{19}$ het vervreemdingsverbod $^{20}$ en de last van lijfrente ${ }^{21}$ kunnen op deze manier als voorwaarden aan een hand- of bankgift worden verbonden.

Voor de schenking van (aandelen in) familiale vennootschappen en familiale ondernemingen heeft de afschaffing van de route van een buitenlandse notaris in het Vlaams Gewest in beginsel ${ }^{22}$ geen belang. Het tarief van de schenkbelasting bedraagt $0 \%$. Registratie van de schenking door een Belgische notaris leidt niet tot schenkbelasting. ${ }^{23}$

\section{De betekenis van de woonplaats}

\subsection{Nationale woonplaatsbepaling}

De nieuwe registratieverplichting voor schenking van roerende goederen heeft betrekking op schenkingen door 'Belgische rijksinwoners'. Dat kunnen Belgische onderdanen zijn, Nederlandse onderdanen, maar ook onderdanen van andere landen, zoals bijvoorbeeld Frankrijk of Zwitserland. De nieuwe bepaling van artikel 19, lid 1, 6e van het Federale Wetboek Registratie-, Hypotheek- en Griffierechten vermeldt in algemene zin 'in het buitenland verleden notariële akten'.

Door de koppeling van de registratieverplichting aan het rijksinwonerschap is het belangrijk vast te stellen wanneer iemand als zodanig wordt aangemerkt.

Evenals in Nederland wordt ook in België onderscheid gemaakt tussen het civielrechtelijke begrip woonplaats ${ }^{24}$ en het fiscale. Zo oordeelde rechtbank Gent in een arrest van 14 september 1995:25 'dat de fiscale woonplaats wordt gekenmerkt door een bepaalde bestendigheid of continuïteit, onafhankelijk van de burgerlijke

18. De schenking mag niet worden ingebracht in een huwelijksgemeenschap of een beding van aanwas in huwelijkse voorwaarden.

19. Als de begiftigde voor de schenker overlijdt, keert het geschonkene terug naar de schenker.

20. De begiftigde mag tijdens een bepaalde periode het geschonkene niet verkopen of zelf wegschenken.

21. De begiftigde is verplicht gedurende een bepaalde periode de schenker een bepaald bedrag te betalen.

22. Het honorarium van de Belgische notaris is wel hoger.

23. Art. 2.8.6.0.3 VCF.

24. Art. 103 Belgisch BW; het voornemen om op een bepaalde plaats zijn hoofdverblijf te vestigen

25. R.G.F. 1996, 105, noot L. Hinnekens. woonplaats en van de nationaliteit, en die tot stand komt en bevestigd wordt door een geheel van vastgestelde omstandigheden, in het bijzonder de plaats van het werkelijk wonen en meer bepaald de plaats waar het gezin is gevestigd'.

Aangezien de registratieverplichting een fiscale aangelegenheid betreft, ga ik hierna uitsluitend in op de fiscale woonplaats.

Volgens artikel 2, § 1, 1e van de Wet Inkomstenbelasting 1992 (WIB 1992) worden onder rijksinwoners verstaan:

'a. de natuurlijke personen die in België hun woonplaats of de zetel van hun fortuin $\left[{ }^{26}\right]$ hebben gevestigd (...). De vestiging van de woonplaats of van de zetel van het fortuin in België wordt naar de omstandigheden beoordeeld. Evenwel worden, behoudens tegenbewijs, geacht hun woonplaats of de zetel van hun fortuin in België te hebben gevestigd de natuurlijke personen die in het Rijksregister van de natuurlijke personen zijn ingeschreven. Voor gehuwden (...) wordt de fiscale woonplaats bepaald door de plaats waar het gezin is gevestigd.'

De bewijslast inzake de hoedanigheid van rijksinwoner berust op de belastingadministratie, maar door de invoering van twee bewijsvermoedens, te weten: (1) de inschrijving in het Rijksregister van natuurlijke personen en (2) voor gehuwden de plaats waar het gezin is gevestigd, heeft de wetgever deze taak enigszins verlicht. Is degene die door de administratie als rijksinwoner wordt aangemerkt van mening dat dit niet correct is, dan kan hij met alle hem ter beschikking staande middelen proberen het tegenovergestelde te bewijzen.

Volgens vaste Belgische jurisprudentie wordt de woonplaats van een belastingplichtige gekenmerkt als de plaats waar iemand werkelijk woont en die een zekere bestendigheid kent. Om in België als een niet-inwoner te worden aangemerkt, is het noodzakelijk dat het verblijf in het buitenland gekenmerkt wordt door een zekere bestendigheid en continuiteit. Daarbij is het niet noodzakelijk dat iemand de intentie heeft zich permanent of ten minste zeer langdurig in het buitenland te vestigen.

In Nederland wordt de fiscale woonplaats volgens artikel 4 van de Algemene wet inzake rijksbelastingen (AWR) bepaald aan de hand van de omstandigheden. Bij deze omstandigheden gaat het om de materiële werkelijkheid, waarbij het aan de rechter is om te beoordelen welke omstandigheden in het individuele geval van belang zijn; de wetgever heeft namelijk geen bijzondere betekenis willen toekennen aan bepaalde categorieën

26. Met 'zetel van fortuin' wordt bedoeld de plaats van waaruit het vermogen van iemand wordt beheerd en die door een bepaalde eenheid wordt gekenmerkt. Rechtbank Brussel 11 december 1998, Fisc. Koer. 1999, 280 besliste dat wanneer een jonge werknemer, die slechts een gering materieel vermogen bezit, een patrimonium opbouwt door middel van zijn arbeidskracht, hieruit moet worden afgeleid dat de plaats waar hij zijn beroep uitoefent en waar hij de vruchten van zijn arbeid geniet, tegelijkertijd de zetel van zijn fortuin is. 
omstandigheden, zoals de sociale of economische binding met een land. Vanwege het feitelijke karakter van de beoordeling is de rechtspraak voornamelijk die van feitenrechters.

Naar aanleiding van een WOB-verzoek heeft het Ministerie van Financiën op 17 december $2018^{27}$ informatie verstrekt over het beleid ten aanzien van het vaststellen van de fiscale woonplaats. Wat bij de opsomming van relevante feiten opvalt, is dat buitenlandse omstandigheden geen rol lijken te spelen bij de beoordeling of er een duurzame betrekking is met Nederland; ${ }^{28}$ het beleid richt zich op wat de binding is van de betreffende belastingplichtige met Nederland. Daarin lijkt een zekere overeenkomst met de Belgische fiscale woonplaatsbepaling te bestaan, maar het is niet ondenkbaar dat in een concreet geval iemand inwoner is van zowel Nederland als België.

\subsection{Federale woonplaatsbepaling en verdeling van de heffingsrechten}

Binnen de federale staat België is als uitvoering van het Lambermontakkoord ${ }^{29}$ de bevoegdheid tot het vaststellen van, onder meer, de schenk- en erfbelasting toegedeeld aan de Belgische Gewesten: het Brussels Hoofdstedelijk, het Waals en het Vlaams Gewest. Vanwege het feit dat de Gewesten, met het Vlaams Gewest voorop, veelvuldig gebruik hebben gemaakt van de hun toegekende bevoegdheden, is het gevolg daarvan een weinig coherente kluwen van fiscale gunsttarieven. Voor belastingplichtigen kan het aantrekkelijk zijn zich juist in dát Gewest te vestigen dat, rekening houdend met zijn vermogensrechtelijke en/of familiale situatie, fiscaal het meest gunstig is om de laatste levensjaren door te brengen of om er een schenking te doen.

Tot 2001 werd door de federale wetgever voor de vraag waar schenk- of erfbelasting was verschuldigd als hoofdregel aangeknoopt bij de hoofdverblijfplaats van de schenker of bij de plaats waar de nalatenschap openvalt. Artikel 1 van het Federale Wetboek Successierechten definieert het begrip rijksinwoner als volgt: 'hij die op het ogenblik van zijn overlijden binnen het Rijk zijn domicilie of zetel van fortuin heeft gevestigd'. Uit deze omschrijving blijkt dat uitsluitend met de toestand op sterfdatum rekening wordt gehouden. Dat is echter niet noodzakelijkerwijs de plaats waar iemands fiscale woonplaats was.

Gelijktijdig met de uitbreiding van de fiscale bevoegdheden van de Gewesten in 2001 is in artikel 7 van de bijzondere wet van 31 juli 2001 door middel van het zogenoemde lokalisatiecriterium bepaald wanneer welke Gewestbelasting van toepassing is. Op basis van dit criterium wordt bepaald hoe de opbrengst van deze belastingen dient te worden verdeeld over de Gewesten.

27. Besluit WOB-verzoek inzake afgegeven verdragsverklaringen en vaststellen fiscale woonplaats natuurlijke personen; 2018-0000214023.

28. Zie A.J.C. Perdaems, Woonplaats gewobt: beleid in strijd met jurisprudentie, Tax live 5 februari 2019.

29. 2000-2001, de vijfde staatshervorming.
Waar iemand zijn fiscale woonplaats voor de erf- en schenkbelasting heeft, heeft de federale wetgever in 2001 als volgt gedefinieerd: 'de plaats waar de overledene of de schenker zijn werkelijke, effectieve, voortdurende woonplaats heeft gevestigd, de plaats waar hij zijn domus, zijn familie, het centrum van zijn bedrijvigheid, de zetel van zijn akten en van zijn bezigheden had'. ${ }^{30}$

De vraag is welk van deze criteria doorslaggevend is, ervan uitgaande dat deze in veel gevallen niet allemaal naar dezelfde plaats verwijzen.

Ervan uitgaande dat op basis van de vorenstaande definitie de fiscale woonplaats van iemand is bepaald, betekent de combinatie met het lokalisatiecriterium concreet het volgende. Voor een rijksinwoner die in de afgelopen vijf jaren voorafgaande aan de schenking op meer dan één plaats in België heeft gewoond, wordt de plaats waar hij tijdens die vijf jaren het langst zijn fiscale woonplaats had, doorslaggevend geacht voor de heffing van schenkbelasting. Als de fiscale woonplaats van de schenker tijdens de periode van vijf jaar in het buitenland was en op het moment van de schenking in België, dan wordt aangeknoopt bij de plaats waar schenker op het moment van de schenking zijn fiscale woonplaats had.

Voor niet-rijksinwoners bepaalt in geval van schenking van een onroerend goed de plaats van ligging de toepasselijke Gewestbelasting. ${ }^{31}$

\subsection{Tarieven van de drie Gewesten}

De tarieven van de drie Gewesten lopen zowel voor schenking van roerende als voor schenking van onroerende goederen uiteen.

Voor schenkingen van roerende goederen geldt in het Vlaams Gewest een proportioneel tarief van 3\% in de rechte lijn en tussen partners. Schenkingen tussen alle andere personen wordt belast tegen 7\%. In het Brussels Hoofdstedelijk Gewest geldt eveneens een tarief van 3\% in de rechte lijn, tussen echtgenoten en samenwoners. Schenkingen tussen alle andere personen worden belast tegen 7\%. In het Waals Gewest worden schenkingen in de rechte lijn, tussen echtgenoten en wettelijk samenwonenden belast met 3,3\%. Tussen alle andere personen is het tarief van $5,5 \%$ van toepassing.

Voor schenking van onroerende goederen liggen de tarieven hoger; zo kunnen in het Vlaams Gewest, afhankelijk van de omvang van de schenking, schenkingen in de rechte lijn belast worden tegen minimaal 3\% en maximaal $27 \%$. Tussen alle andere personen gelden schenkingstarieven van minimaal $10 \%$ tot maximaal $40 \%$.

\section{Dubbele heffing?}

In Nederland is de verkrijger van een schenking c.q. gift schenkbelasting verschuldigd als de schenker ten tijde

30. Wet van 7 maart 2002, MvT Parl. St. Kamer, 2001-2002, 1577/1, 6 .

31. Circulaire 20 oktober 2005, nr. 12/2005, www. Fisconet.be. 
van de schenking in Nederland woonde. ${ }^{32}$ Gaat het om een schenking van ouders aan kinderen, dan is, afhankelijk van de omvang van de schenking en van de toepasselijke vrijstelling, het tarief van respectievelijk $10 \%$ en $20 \%$ van toepassing. Bij een schenking tussen alle andere personen gelden tarieven van respectievelijk $30 \%$ en $40 \%$.

Vanwege het feit dat de aanbieding ter registratie van een schenking van roerende goederen in België in een aantal gevallen niet meer vrijwillig is en wordt gekoppeld aan de status van Belgisch rijksinwoner, kan het vaker voorkomen dat schenkingen door in België wonende Nederlandse onderdanen binnen de tienjaarsperiode van artikel 3 van de Successiewet 1956 (SW 1956) in beide landen belastbaar zijn.

In afwezigheid van een bilateraal verdrag ter voorkoming van dubbele heffing van schenk- en erfbelasting kan de verkrijger van de schenking een beroep doen op het Nederlandse Besluit voorkoming dubbele belasting 2001. Voor schenkingen zijn via de bepaling van artikel 50 van dit besluit de voorkomingsregels van artikel 48 van toepassing: in geval van fictief Nederlands inwonerschap wordt de in het buitenland verschuldigde belasting, als de schenker daar zijn werkelijke woonplaats heeft, verrekend met de Nederlandse schenkbelasting tot maximaal het bedrag dat in Nederland aan belasting is verschuldigd.

In geval van schenkingen tussen ouders en kinderen, maar ook die tussen alle andere personen, zal de Belgische schenkbelasting, gelet op de gematigde tarieven, verrekend kunnen worden met de Nederlandse schenkbelasting. Maar bedacht dient te worden dat over het bedrag van de in Nederland aangewende schenkingsvrijstelling de Belgische schenkbelasting niet wordt verrekend. Dat heeft te maken met het feit dat artikel 48 Besluit voorkoming dubbele belasting 2001 alleen een vermindering geeft 'voorzover' er dubbele heffing zou optreden. Zou de algemene eenmalig verhoogde Nederlandse schenkingsvrijstelling van $€ 26.861$ worden benut, of zou de eenmalige schenkingsvrijstelling voor de eigen woning van $€ 105.302$ worden ingezet bij een roerende schenking, dan is over dat bedrag, afhankelijk van het Belgische Gewest waar de schenker woont, 3\%, $3,3 \%$ of $7 \%$ Belgische schenkbelasting verschuldigd.

In veel gevallen zal de Nederlandse onderdaan die rijksinwoner is van België de Nederlandse tienjaarstermijn uitzitten om pas daarna een roerende schenking te doen. De Nederlandse schenk- en erfbelastingregels zijn dan uitgewerkt. Iets wat, gelet op de Belgische definitie van rijksinwonerschap, mijns inziens meer een rol kan gaan spelen, is de vraag in hoeverre iemand een dubbele woonplaats heeft. De verrekening van schenkbelasting kan dan in de knel komen, omdat het Nederlandse Besluit voorkoming dubbele belasting 2001 niet in een oplossing voor die situatie voorziet. België en Nederland zijn buurlanden en om die reden is het niet uitgesloten dat iemand als (rijks)inwoner van beide landen wordt aangemerkt. Het is heel goed voorstelbaar dat iemand vanwege zijn werkzaamheden in twee landen een woning ter beschikking staat, en dat het gezinsaanknopingspunt verwatert naarmate de kinderen ouder worden en het huis verlaten.

Uit de lange lijst van Nederlandse jurisprudentie over artikel 4 AWR blijkt dat de fiscale woonplaats geregeld niet eenduidig is vast te stellen. Om die reden is de mogelijkheid van een dubbele woonplaats door de Nederlandse Hoge Raad erkend, ${ }^{33}$ zij het met de kanttekening dat het slechts om uitzonderingsgevallen zal gaan. De dubbele heffing die uit een dubbele woonplaats voortvloeit, kan alleen maar worden voorkomen wanneer een bilateraal verdrag wordt gesloten ter vermijding van dubbele heffing. In de door Nederland gesloten verdragen die zijn gebaseerd op het OESOmodelverdrag is voor die situatie de zogenoemde tiebreaker opgenomen, die voor deze dubbele woonplaats een oplossing biedt. Maar of het sluiten van een bilateraal verdrag ter vermijding van dubbele schenk- en erfbelasting Nederland-België ooit op de politieke agenda komt, betwijfel ik ten zeerste.

\section{Slot}

In het bovenstaande ben ik ingegaan op de Belgische federale wetswijziging die ervoor moet zorgen dat in meer gevallen dan voorheen in België over schenking van roerende goederen schenkbelasting wordt voldaan. Of dat werkelijk gebeurt, zal de praktijk moeten uitwijzen, maar gezien de Belgische voorkeur om schenkingen van roerende goederen onder voorbehoud van het recht van vruchtgebruik te doen, zou dit weleens het geval kunnen zijn. Hand- en bankgiften en schenking van levensverzekeringen blijven echter vrij van schenkbelasting. Door de in beginsel verplichte registratie van schenking van roerende goederen in België wordt de invulling van het fiscale woonplaatsbeginsel meer van belang. Als gevolg van de Nederlandse eenzijdige regeling ter voorkoming van dubbele belastingheffing zal dubbele heffing bij deze schenkingen zich niet snel voordoen. Waar Nederlandse onderdanen die als Belgisch rijksinwoner worden aangemerkt op bedacht moeten zijn, is dat wanneer ze binnen de tienjaarstermijn van artikel $3 \mathrm{SW} 1956$ een schenking van roerende goederen doen, over de Nederlandse vrijstellingsbedragen Belgische schenkbelasting verschuldigd is. De reparatiewetgeving die op 15 december 2020 in werking is getreden, betreft niet alleen de kaasroute. Die route vormde voor de indieners van het Belgische wetsvoorstel de reden tot aanpassing van de wet. Er zijn echter ook Belgische rijksinwoners die voor een roerende-schenkingsakte de Franse of Zwitserse notaris opzochten. Ook voor hen geldt de aanpassing. 